\title{
DO PLANO DIRETOR ÀS OPERAÇÕES URBANAS CONSORCIADAS
}

\author{
Carlos Antônio Brandão* \\ * Universidade Federal do Rio de Janeiro, Instituto de Pesquisa e Planejamento Urbano e Regional, \\ Rio de Janeiro, RJ, Brasil.
}

NOBRE, E. Do plano diretor às operações urbanas consorciadas. A ascensão do discurso neoliberal e dos grandes projetos urbanos no planejamento paulistano. São Paulo: Annablume, 2019.

A recente publicação do livro do professor da FAU-USP Eduardo Alberto Cuscé Nobre, Do plano diretor às operações urbanas consorciadas: a ascensão do discurso neoliberal e dos grandes projetos urbanos no planejamento paulistano (2019), traz importante contribuição no campo do planejamento urbano e regional para o atual debate brasileiro, em momento em que o país e o mundo passam por transformações radicalizadas.

A obra, de grande fôlego, está imersa no complexo e contraditório contexto contemporâneo e avalio que possa auxiliar na seguinte problematização, fundamental para nossa área neste momento: até que ponto é possível promover políticas urbanas consequentes, democráticas e efetivas em um mundo parametrizado, normalizado, marquetizado e perplexamente dominado pelo mercado e pelo neoliberalismo (CAHILL et al., 2019; BERNDT et al., 2020)?

$\mathrm{O}$ acelerado tempo conjuntural em que estamos vivendo (que expressa inédita condensação do tempo estrutural) revela a tentativa radical (vencedora pelo menos na atual quadra histórica) de disembedded do mercado em relação às forças sociais. Trata-se de conjuntura de conexões contraditórias, no sentido de Doreen Massey e Stuart Hall, que parece confirmar a vitória do "moinho satânico" da mercantilização extrema, no sentido apontado por Karl Polanyi.

A cidade, lócus decisivo da reprodução da vida social, com todo seu potencial de se afirmar como espaço privilegiado para a abertura dos horizontes das infinitas possibilidades para a vida digna, democrática e cidadã, vai sendo trans- 
formada em mera plataforma para a exploração das possibilidades curto-prazistas de lucratividade. Das utopias dos planos de vidas das pessoas em uma sociedade urbana emancipatória, vai se convertendo em mero lócus de planos de negócios, subordinados à reprodução ampliada dos negócios dos capitais privados e das distopias antidemocráticas.

O livro objetiva estudar os processos urbanos e a tentativa de sua regulação pública, com base no estudo de uma realidade concreta do espaço que é o centro e o núcleo duro do capitalismo brasileiro, isto é, seu lugar mais privilegiado, em termos de evolução material e acumulação de capital. Ou seja, o estudo examina justamente o lócus mais avançado de desenvolvimento das forças produtivas materiais, de concentração urbano-metropolitana da riqueza (mas também da desigualdade, da segregação e da pobreza) da América Latina.

Conforme afirma Eduardo Nobre: "A maneira com que os órgãos públicos passaram a ver o urbanismo e o planejamento urbano mudou do controle à produção do espaço, através da legislação urbanística de uso e ocupação do solo, para um enfoque 'mercadológico' de estímulo ao desenvolvimento imobiliário e à atração de empresas, muitas vezes negligenciando os impactos socioespaciais locais” (p. 82).

Na verdade, transitamos do planejamento urbano tradicional, compreensivo e racionalista, para o planejamento urbano estratégico, originado no âmbito militar e transposto ao mundo privado corporativo empresarial. No caso brasileiro, tanto o primeiro como o último pouco ou nada consideraram os anseios da maioria da população, sempre marcados pela regulação pública fraca do mercado privado forte (BRANDÃO, 2016). As experimentações do planejamento tradicional foram burocráticas e autoritárias, e as do planejamento estratégico, mercadistas. O que elas têm em comum é o fato de ambas terem sido concebidas e implementadas com baixa ou nenhuma democracia.

No já longo curso do processo de neoliberalização, o paradigma da política urbana passou por grande reformulação. A metodologia de avaliação da política urbana mudou da análise do lado da demanda, do plano diretor, do orçamento de longo prazo, da regulação e do planejamento, para a análise do lado da oferta de mercado, da viabilização dos negócios privados dos projetos específicos, embora geralmente amparados pelo setor público. Ocorreu a viagem das narrativas ideológicas conservadoras, dos conceitos e das tentativas de imposição de experimentações exógenas. Tais experimentações foram marcadas pelo hibridismo e pela adaptabilidade a cada contexto e circunstância, geralmente buscando atender às necessidades das demandas imediatas dos mercados imobiliários e financeiros, 
que requerem a criação de excepcionalidades e a flexibilização de normas etc., o que leva a um urbanismo customizado, elitista e de retorno rápido.

São experimentações aderentes, isto é, adaptadas aos contextos socioespaciais, econômicos e políticos em que se inscrevem. Por exemplo, no Rio de Janeiro se experimentou o planejamento estratégico e, em São Paulo, a ação foi mais direta, pois se deu por intermédio da adoção das Operações Urbanas Consorciadas (OUC), como resultado de estudos de instrumentos urbanísticos semelhantes utilizados nos países centrais, realizados desde a década de 1970, e cuja replicação se buscou efetivar de forma circunstanciada.

O texto tem inúmeros méritos, com destaque, sobretudo, para a capacidade de síntese, sistematização e construção de articulações criativas de diversas temáticas e dimensões do urbanismo e das políticas urbanas, seja na dimensão teórica, seja na empírica. Pelo menos três escalas são percorridas em todos os capítulos, nos prismas das teorias e conceitos e das políticas urbanas: mundial, nacional e local.

O principal foco da pesquisa empreendida - a trajetória das experimentações da política urbana paulistana - está bem articulado com outros contextos, escalas e paisagens geoinstitucionais.

O livro nos proporciona um interessante transitar também pela escala mundial do capitalismo central ao longo da história do urbanismo e depois dos desdobramentos históricos e geográficos do atual processo de neoliberalização.

Em suma, apresenta o planejamento urbano nos países centrais desde o século XVIII; examina, em análise minuciosa, desde a constituição do planejamento urbano em São Paulo, o surgimento do urbanismo paulistano, até as variadas experimentações de políticas urbanas na capital. Discute as transformações nas teorias urbanas, ao longo do tempo, culminando com as abordagens que foram impostas em decorrência da crise mundial, da globalização e do neoliberalismo.

Parte do urbanismo e sua evolução. Esse campo do saber e da ação, concebido originalmente nos países centrais, detinha, de sua origem até, grosso modo, o final da década de 1970, uma concepção globalizante e integrada da cidade. A ação racionalizadora pública e coletiva, apontava-se, pelo menos teoricamente, deveria ser integradora. Eduardo nos fala ainda das experiências internacionais, como as do Flächennutzungsplan da Alemanha; Master ou Comprehensive Plan dos Estados Unidos; Plano Regulatore na Itália; Plan d’Urbanisme Directeur da França; Ruimtelijke Structuurvisie da Holanda; Development Plan do Reino Unido.

Aquele urbanismo central desembarcou na realidade dos países subdesenvolvidos e periféricos, muitas vezes com nenhuma ou reduzidas mediações teóricas e históricas. Com o processo de neoliberalização que foi se desenhando e avançando desde o final da década de 1970, a partir de suas experimentações, adaptações, hi- 
bridismo e movimentos contraditórios conjunturais, aos poucos se consolidou uma visão focalizada e de intervenções urbanas pontuais, fragmentárias e localizadas em áreas específicas.

O movimento metodológico foi brilhantemente percorrido na obra aqui resenhada, ao abordar desde as questões mais abstratas de nosso campo, até suas determinações histórico-concretas, passando pela construção de periodizações precisas, da dinâmica de produção do espaço no contexto específico do capitalismo periférico e dependente, com ênfase no caso particular do município de São Paulo nas últimas quatro décadas.

É apresentada uma análise minuciosa da formulação e da implementação de políticas e intervenções urbanas no município de São Paulo durante quarenta anos, entre 1975 e 2014, identificando as influências e as matrizes ideológicas de seu discurso, o aparato institucional erguido, as disputas de interesses e, por fim, os principais ganhadores e perdedores no que se refere a esse processo.

Eduardo elabora uma periodização precisa, de longo curso, do planejamento paulistano, ao analisar seus vários ciclos e momentos: desde o surgimento do urbanismo paulistano (do final do século XIX até 1930); a ascensão do rodoviarismo (de 1930 a 1945); a influência dos consultores estrangeiros (de 1945 a 1967); o PDDI e a Lei de Zoneamento; a fase prospectiva (de 1975 a 1985); as primeiras experiências de implementação de parcerias público-privadas, das Operações Interligadas à Operação Urbana Anhangabaú (de 1986 a 1992); os governos Paulo Maluf (19931996), Celso Pitta (1997-2000) e Marta Suplicy (2001-2004).

Sua análise busca apreender a dinâmica das coalizões, dos aparatos institucionais e burocráticos, dos instrumentos e mecanismos utilizados em cada conjuntura política. $\mathrm{O}$ autor realiza um balanço muito rigoroso dos resultados da implementação das Operações Urbanas Consorciadas e revela como o campo de atuação do planejamento urbano no município de São Paulo se configurou contraditoriamente, em face da viagem, da tradução e da adaptação de ideias, assim como da transmissão interjurisdicional de modelos dos países centrais para os periféricos, o que ocorreu com mais ímpeto a partir das décadas de 1960 e 1970.

Eduardo argumenta que o processo de neoliberalização, com sua ideologia e forma de atuação, acabou por reforçar as mazelas históricas e estruturais da destituição, da desigualdade, da segregação socioespacial das classes sociais, reafirmando as faces mais regressivas e perversas da atuação do poder público, pela via do planejamento urbano paulistano de investimentos em infraestruturas viárias, que na verdade engendravam horizontes renovados de expansão imobiliária nos eixos e vetores de interesse do mercado, em detrimento do direito à cidade para a maioria da população. 
O livro em foco demonstra o que de melhor o ambiente intelectual latino-americano crítico produziu no que diz respeito à interpretação dos nossos processos socioespaciais específicos. Tais processos devem ser analisados em seu movimento histórico, contraditório e dinâmico, em um percurso teórico e empírico das interconexões entre práticas e estruturas, sempre observadas as variadas escalas desses processos.

Em nosso campo crítico, é preciso, em um esforço coletivo, sempre avançar, sofisticar e aprofundar a investigação das coalizões de poder, desvendando sua natureza, estrutura e dinâmica, com a averiguação da lógica singular de funcionamento das frações de capitais envolvidos, bem como as facções de interesse que cimentam tais coalizões. Essa complexidade metodológica é importante para explicitar melhor as dificuldades de investigação da perspectiva crítica: a renovada intransparência e os formatos mutantes das alianças políticas conservadoras contra o direito à cidade.

O livro, entre outras grandes contribuições, pode auxiliar nos esforços coletivos de investigação da nossa área de conhecimento e prática, para que avancemos na condução de pesquisas específicas das distintas rodadas de neoliberalização das últimas décadas no Brasil, que lançam mão de dispositivos, mecanismos e instrumentos bastante diferenciados de experimentações rerregulatórias, com repercussões variadas nos âmbitos social e espacial. Estudos bem contextualizados e comparativos são sempre muito bem-vindos.

Do plano diretor às operações urbanas consorciadas: a ascensão do discurso neoliberal e dos grandes projetos urbanos no planejamento paulistano, do professor Eduardo Nobre, demonstra acurado esforço de pesquisa e sistematização e uma análise aprofundada e contextualizada da realidade brasileira e paulistana no campo dos estudos urbanos. Recomendo fortemente a leitura e o debate dessa obra.

\section{Referências bibliográficas}

BERNDT, C.; PECK, J.; RANTISI, N. (Eds.) Market/place: exploring spaces of exchange. Newcastle upon Tyne: Agenda Publishing, 2020.

BRANDÃO, C. A. Espaços da destituição e as políticas urbanas e regionais no Brasil: uma visão panorâmica. Nova Economia, Belo Horizonte, v. 26, número especial, p. 1097-1132, 2016.

CAHILL, D. et al. (Eds.). The Sage Handbook of Neoliberalism. Los Angeles: Sage, 2019.

NOBRE, E. Do plano diretor às operações urbanas consorciadas. A ascensão do discurso neoliberal e dos grandes projetos urbanos no planejamento paulistano. São Paulo: Annablume, 2019. 


\section{Carlos Antônio Brandão}

Doutor, livre-docente e titular pela Unicamp. É professor titular do Instituto de Pesquisa e Planejamento Urbano e Regional da Universidade Federal do Rio de Janeiro (IPPUR/UFRJ). Bolsista CNPq.

Email: brandaoufrj@gmail.com

ORCID: 0000-0002-9014-6681

Submissão: 18 de dezembro de 2019.

Aprovação: 10 de fevereiro de 2020.

Como citar: BRANDÃO, C. A. Eduardo Nobre. Do plano diretor às operações urbanas consorciadas. Revista brasileira de estudos urbanos e regionais. V.22, E202008pt, 2020. DOI 10.22296/2317-1529.rbeur.202008pt

Artigo licenciado sob Licença Creative Commons CC BY-NC 4.o.

https://creativecommons.org/licenses/by-nc/4.o/deed.pt_BR 